\title{
The first report of the seroprevalence of antibodies against Bartonella spp. in water buffaloes (Bubalus bubalis) from South Thailand
}

\author{
Sumalee Boonmar ${ }^{1}$, Phirabhat Saengsawang1(D), Watcharapong Mitsuwann", ${ }^{1,2}$ Decha Panjai ${ }^{3}$, Kamchai Kidsin ${ }^{4}$, \\ Chalutwan Sansamur ${ }^{1}$ and Ittidet Wichianrat ${ }^{1}$
}

1. Akkhraratchakumari Veterinary College, Walailak University, Thasala, Nakhon Si Thammarat, 80160, Thailand;

2. Research Center of Excellence in Innovation of Essential Oil, Walailak University, Nakhon Si Thammarat 80160, Thailand; 3. Department of Medical Sciences, National Institute of Health, Ministry of Public Health, Nonthaburi, 11000, Thailand; 4. Animal Health Section, The Eight Regional Livestock Development, Surat Thani 84000, Thailand. Corresponding author: Sumalee Boonmar, e-mail: sumalee.bo@wu.ac.th

Co-authors: PS: phirabhat.sa@wu.ac.th, WM: watcharapong.mi@wu.ac.th, DP: decha.p@dmsc.mail.go.th, KK: jap.hawk@gmail.com, CS: chalutwan.sa@wu.ac.th, IW: ittidet.wi@wu.ac.th Received: 02-09-2021, Accepted: 08-11-2021, Published online: 24-12-2021

doi: www.doi.org/10.14202/vetworld.2021.3144-3148 How to cite this article: Boonmar S, Saengsawang $P$, Mitsuwan W, Panjai D, Kidsin K, Sansamur C, Wichianrat I (2021) The first report of the seroprevalence of antibodies against Bartonella spp. in water buffaloes (Bubalus bubalis) from South Thailand, Veterinary World, 14(12): $3144-3148$.

\begin{abstract}
Background and Aim: Bartonellosis is an emerging worldwide zoonosis caused by bacteria belonging to the genus Bartonella. Several studies have been conducted on the prevalence of Bartonella infections from animals and humans, including reports from wild and domestic ruminants. However, there has been only one report of Bartonella infection in water buffaloes from the northeastern part of Thailand. Moreover, the seroprevalence of Bartonella spp. in water buffaloes still remains unknown. This study was conducted to explore the prevalence of Bartonella spp. among water buffaloes from South Thailand using molecular and serological techniques.
\end{abstract}

Materials and Methods: A total of 312 samples (156 blood and 156 sera) of 156 water buffaloes from 29 farms in Phatthalung Province, South Thailand, were collected from January to March 2021. All samples were screened for Bartonella spp. using polymerase chain reaction and indirect immunofluorescence assay.

Results: The seroprevalence of antibodies against three Bartonella spp. was $16.03 \%(25 / 156,95 \%$ confidence interval: 10.65-22.74\%), and among 25 water buffaloes with seroprevalence, $56 \%, 20 \%$, and $24 \%$ were positive for antibodies against Bartonella henselae, Bartonella vinsonii subspp. berkhoffii, and Bartonella tamiae, respectively. No significant difference was detected among seroprevalence, gender, age, and ectoparasite infestation.

Conclusion: This is the first report of the seroprevalence of antibodies against $B$. henselae, B. vinsonii subspp. berkhoffii, and B. tamiae in water buffaloes from South Thailand. Further studies are required on the epidemiology of Bartonella infection among water buffaloes, related personnel, and ectoparasites.

Keywords: Bartonella henselae, Bartonella tamiae, Bartonella vinsonii subspp. berkhoffii, immunofluorescence assay, seroprevalence, water buffaloes.

\section{Introduction}

Bartonellosis, an emerging zoonosis, is responsible for causing a variety of clinical syndromes in humans and animals and is associated with significant morbidity and mortality in humans worldwide $[1,2]$. A microorganism in the genus Bartonella is the major causative agent of this disease. Bartonella spp. are Gram-negative fastidious oval bacteria that infect mammalian erythrocytes and endothelial cells of the host. It is well known that some Bartonella spp. are the cause of a wide spectrum of human illnesses such as cat scratch disease, chronic bacteremia, fever, and endocarditis [2]. It has been reported that human Bartonellosis is caused by Bartonella henselae,

Copyright: Boonmar, et al. Open Access. This article is distributed under the terms of the Creative Commons Attribution 4.0 International License (http://creativecommons.org/licenses/ by/4.0/), which permits unrestricted use, distribution, and reproduction in any medium, provided you give appropriate credit to the original author(s) and the source, provide a link to the Creative Commons license, and indicate if changes were made. The Creative Commons Public Domain Dedication waiver (http:// creativecommons.org/publicdomain/zero/1.0/) applies to the data made available in this article, unless otherwise stated.
Bartonella bacilliformis, and Bartonella quintana [3]. Furthermore, various species of the pathogens, including Bartonella bovis, B. henselae, and Bartonella clarridgeiae, have been detected from several animals, including buffalo, dog, and cat [4,5]. Mammalian animals such as buffaloes are also considered reservoir hosts and can transmit pathogens to humans.

Water buffaloes (Bubalus bubalis) are one type of cattle belonging to the family Bovidae and subfamily Bovinae [6]. Buffaloes are agriculturally and economically important animals in several countries, including Thailand. They are commonly infested by numerous ectoparasites that are considered vectors of hemoparasites, including Bartonella spp. The major transmission route of this bacterium is through biting from the arthropod vectors such as ticks, mites, lice, fleas, and flies to animals and humans $[7,8]$. Previous studies have reported the infection of Bartonella spp. in buffaloes and the detection of bacterial species from buffalo samples [4,9]. There is also a report of Bartonella infection in water buffaloes from the northeastern and middle parts of Thailand [4]. However, the 
seroprevalence of Bartonella spp. in water buffaloes in Thailand still remains unknown.

Therefore, the aim of the study was to explore the seroprevalence of Bartonella spp. in water buffaloes in 29 farms in South Thailand using polymerase chain reaction (PCR) and indirect immunofluorescence assay (IFA).

\section{Materials and Methods}

\section{Ethical approval}

The study was approved by the Institutional Animal Care and Use Committee of the National Institute of Health (NIH), Thailand.

\section{Study period and location}

The study was conducted from January to March 2021. The samples were collected from Phatthalung providence of Thailand. The samples were processed at Department of Medical Sciences, NIH Laboratory, Ministry of Public Health, Nonthaburi, Thailand.

\section{Sample collection}

We calculated the sample size based on 4124 water buffaloes using the Epitools program (www. epitool.net) with $95 \%$ confidence interval $(\mathrm{CI}), 0.05$ precision, and 0.1 prevalence [4] in Thailand. The result showed that 133 samples needed to be collected. Overall, 312 blood and sera samples of 156 water buffaloes from 29 farms in Phatthalung Province were collected. Approximately $10 \mathrm{ml}$ of blood was aseptically collected from the jugular vein of each water buffalo and transferred to EDTA-containing collection tubes. In addition, $5 \mathrm{ml}$ of blood was collected into a plain tube, and the obtained serum was stored in a sterile microcentrifuge tube. The gender, age, and health status, including ectoparasite infestation of each water buffalo were recorded. Samples were transported to the Department of Medical Sciences, NIH Laboratory, under chilled conditions and stored at $-20^{\circ} \mathrm{C}$ until processing.

A total of 156 water buffaloes were investigated in this study, comprising 106 females $(67.9 \%)$ and 50 males $(32.1 \%)$. These buffaloes were divided into two age groups as follows: 63 water buffaloes $(40.4 \%)$ were aged $\leq 2$ years and the remaining 93 buffaloes $(59.6 \%)$ were aged $>2$ years. Furthermore, 109 (69.87\%) buffaloes were infested with ectoparasites (lice).

\section{Isolation of Bartonella}

Isolation of Bartonella was done according to a previously described method [10] with modification. Briefly, frozen blood samples were thawed at $25^{\circ} \mathrm{C}$, and then, $200 \mu \mathrm{L}$ of blood was centrifuged. The sediment was mixed with the same volume of medium 199 supplemented with sodium pyruvate and fetal bovine serum (Life Technologies, USA). The mixture was then plated onto brain heart infusion agar (BHIA, Difco, USA) plates containing 5\% defibrinated rabbit blood. The plates were incubated at $35^{\circ} \mathrm{C}$ under $5 \% \mathrm{CO}_{2}$ for 2-4 weeks. This showed the presence of
Gram-negative coccobacilli growing in small, rough, and grayish colonies that required long culture periods, which were tentatively considered as Bartonella organisms. The bacteria were subcultured on the culture media for further characterization.

\section{DNA extraction and PCR amplification}

Bartonella DNA from the samples was identified by the detection of genomic DNA using specific primers by PCR as described previously by Pangjai et al. [10]. The genomic DNA was extracted from each isolate using InstaGene Matrix (BioRad, Hercules, USA). Primers targeting the $\beta$-subunit of RNA polymerase (rpoB) [11] (primer pair sequences $5^{\prime}$ CGCATTGGCTTACTTCGTATG $3^{\prime}$ and $5^{\prime}$ GTAGACTBATTAGAACGCTG $3^{\prime}$ ) and citrate synthase $(g l t A)$ [12] (primer pair sequences 5' AATGCAAAAAGAACAGTAAACA $3^{\prime}$ and $5^{\prime}$ GGGGACCAGCTCATGGTGG 3') were used for PCR analysis. The thermal cycling conditions of PCR included a first denaturation step at $94^{\circ} \mathrm{C}$ for $2 \mathrm{~min}$, followed by 35 cycles of $94^{\circ} \mathrm{C}$ for $30 \mathrm{~s}, 53^{\circ} \mathrm{C}$ for $30 \mathrm{~s}$, and $72^{\circ} \mathrm{C}$ for $1 \mathrm{~min}$, with a final step of $72^{\circ} \mathrm{C}$ for $7 \mathrm{~min}$. Positive and negative controls were included in each experiment. Finally, $10 \mu \mathrm{L}$ volume of each PCR product was subjected to electrophoresis on $1.5 \%$ agarose gels containing ethidium bromide and visualized on a UV transilluminator. The length of PCR products, $825 \mathrm{bp}$ (rpoB primers) and $379 \mathrm{bp}$ (gltA primers) should be observed.

\section{Indirect IFA}

Buffalo sera were screened for antibodies against Bartonella spp. using IFA as described previously by Pangjai et al.[10]. Briefly, $10 \mathrm{ml}$ of blood was centrifuged at $1500 \times \mathrm{g}$ for $15 \mathrm{~min}$ to collect serum. Then, the antigens of Bartonella spp., including B. henselae, B. vinsonii subspp. berkhoffii, and Bartonella tamiae (provided by the US-CDC), were fixed on the slides. Next, $10 \mu \mathrm{L}$ of diluted serum (diluted in PBS containing 5\% skim milk) was placed into the test holes, and the slides were incubated at $37^{\circ} \mathrm{C}$ for $1 \mathrm{~h}$ in a humid chamber. Then, the slides were washed twice with PBS for $15 \mathrm{~min}$. Fluorescein-conjugated goat anti-bovine IgG (KPL Antibody and Conjugates Products, SeraCare Corp, USA) was diluted 1:800 in PBS with $0.001 \%$ Evans blue, and $10 \mu \mathrm{L}$ of the mixture was applied into each hole. The slides were incubated for $1 \mathrm{~h}$ at $37^{\circ} \mathrm{C}$, washed twice with PBS for $15 \mathrm{~min}$, washed again with double-distilled water for $10 \mathrm{~min}$, and then dried before examination under a fluorescence microscope. The intensity of the bacillus-specific fluorescence was scored subjectively from +1 to +4 , and the fluorescence score of +2 at a dilution of 1:16 was considered to be positive. Serum samples were screened at 1:16 dilution, and the positive sample (at 1:16 dilution) was titrated in a series of 2-fold dilutions up to 1:1024. Positive and negative controls were included in the study.

\section{Statistical analysis}

The odds ratio was calculated using "epiR" package embedded in $\mathrm{R}$ program, version 4.02[13]. 
The observed differences were considered to be statistically significant at $p \leq 0.05$.

\section{Results}

Overall, 16.03\%(25/156,95\% CI: $10.65-22.74 \%)$ of the water buffalo sera samples were positive for three Bartonella antigens at the cutoff titer of 1:16. Table-1 shows the seroprevalence of antibodies against three Bartonella antigens, wherein among the 25 positive buffaloes, $56 \%(14 / 25)$ were positive for $B$. henselae antigen only, $20 \%(5 / 25)$ were positive for $B$. vinsonii subspp. berkhoffii antigen only, and $24 \%(6 / 25)$ were positive for $B$. tamiae antigen only. Interestingly, $1(4 \%)$ of the 25 buffaloes was found to be positive for $B$. vinsonii subspp. berkhoffii at the cutoff titer of 1:64. The comparisons of Bartonella spp. seroprevalence assessed by IFA among gender, age, and ectoparasite infestation using univariate analysis are summarized in Table-2. No significant differences were observed among the seroprevalence, gender, age, and ectoparasite infestation. As shown in Table-3, the seroprevalence of antibodies at the herd level was $34.5 \%$ (10/29). Among the 29 farms, 25 positive buffaloes were detected in 10 farms, and each farm contained buffaloes that had positive antibodies against Bartonella spp. Especially in farm 2, there was one buffalo harboring two antibodies against $B$. henselae and B. vinsonii subspp. berkhoffii. However, PCR analysis of any sample did not reveal Bartonella DNA.

Table-1: Seroprevalence of antibodies against

B. henselae, B. vinsonii subspp. berkhoffii, and B. tamiae by IFA.

\begin{tabular}{lccc}
\hline $\begin{array}{l}\text { Antibody } \\
\text { titer }\end{array}$ & B. henselae & $\begin{array}{c}\text { B. vinsonii } \\
\text { subspp. } \\
\text { berkhoffii }\end{array}$ & B. tamiae \\
\hline $1: 16$ & $14 / 25(56 \%)$ & $3 / 25(12 \%)$ & $6 / 25(24 \%)$ \\
$1: 32$ & - & $1 / 25(4 \%)$ & - \\
$1: 64$ & - & $1 / 25(4 \%)$ & - \\
\hline
\end{tabular}

$B$. henselae =Bartonella henselae, $B$. vinsonii=Bartonella vinsonii, B. tamiae=Bartonella tamiae,

IFA=Immunofluorescence assay

\section{Discussion}

This is the first report of the detection of Bartonella spp. in water buffaloes using IFA. Our result showed that $16 \%(25 / 156,95 \%$ CI: $10.65-22.74 \%)$ of the water buffaloes harbored antibodies against three Bartonella spp. We suspected that those buffaloes had been infected with Bartonella in the past. Some authors had reported that higher antibody titers were associated with bacteremia in animals and lower antibody titers might indicate slight bacteremia [14]. However, in our study, Bartonella DNA was not detected using PCR. Due to the limitation of information on the seroprevalence of Bartonella antibodies from buffaloes in Thailand, we could not compare our results with other studies.

Recently, studies have reported the high prevalence of B. bovis, Bartonella chomellii, Bartonella schoenbuchensis, Bartonella capreoli, and Bartonella melophagi infections in ruminants [15-18]. B. bovis infection was reported in $6.8 \%$ of water buffaloes in Thailand [4] and in 4.1\% of wild African buffaloes (Syncerus caffer) in Mozambique, Africa [9], using molecular technique. However, our results showed the presence of antibodies against $B$. henselae, $B$. vinsonii subspp. berkhoffii, and $B$. tamiae, and not against $B$. bovis, in the water buffaloes.

A high prevalence of $B$. henselae infection has been reported in dogs and cats as well. Not only $B$. henselae but also B. vinsonii subspp. berkhoffii was detected in Thai cats [19-21]. Our literature search also showed a report of $B$. tamiae isolated from patients with febrile illness in Thailand who had possible rodent contact and were either dog or cat owners [22]; we also found a report of Bartonella spp. isolated from ectoparasites (chigger mites) and ticks of rodents in Thailand [23].

There are also some reports showing that infected arthropods could transmit Bartonella spp. to humans, such as $B$. henselae from cat fleas [7,24], B. quintana from human body lice [25], and Bartonella spp. from cattle lice [26]. Unfortunately, we collected arthropod

Table-2: Statistical association between the seroprevalence of antibodies against $B$. henselae, B. vinsonii subspp. berkhoffii, B. tamiae, and different factors (univariate analysis).

\begin{tabular}{|c|c|c|c|c|c|c|c|c|c|c|c|c|c|}
\hline \multirow[t]{2}{*}{ Factor } & \multirow[t]{2}{*}{ Total } & \multicolumn{3}{|c|}{$\begin{array}{c}\text { Bartonella spp. } \\
(25 / 156)\end{array}$} & \multicolumn{3}{|c|}{$\begin{array}{c}\text { B. henselae } \\
(14 / 156)\end{array}$} & \multicolumn{3}{|c|}{$\begin{array}{c}\text { B. vinsonii } \\
\text { subspp. berkhoffii } \\
(5 / 156)\end{array}$} & \multicolumn{3}{|c|}{$\begin{array}{l}\text { B. tamiae } \\
(6 / 156)\end{array}$} \\
\hline & & $\mathbf{P}$ & $\mathbf{N}$ & $\mathbf{p}$ & $\mathbf{P}$ & $\mathbf{N}$ & $\mathbf{p}$ & $\mathbf{P}$ & $\mathbf{N}$ & $\mathbf{p}$ & $\mathbf{P}$ & $\mathbf{N}$ & $\mathbf{p}$ \\
\hline \multicolumn{14}{|l|}{ Gender } \\
\hline Female & 106 & 17 & 89 & 1 & 10 & 96 & 1.00 & 4 & 102 & 1 & 3 & 103 & 0.39 \\
\hline Male & 50 & 8 & 42 & & 4 & 46 & & 1 & 49 & & 3 & 47 & \\
\hline \multicolumn{14}{|l|}{ Age } \\
\hline$\leq 2 y$ & 63 & 14 & 49 & 0.13 & 8 & 55 & 0.29 & 3 & 60 & 0.39 & 3 & 60 & 0.69 \\
\hline$>2$ y & 93 & 11 & 82 & & 6 & 87 & & 2 & 91 & & 3 & 90 & \\
\hline \multicolumn{14}{|c|}{ Ectoparasite } \\
\hline Yes & 109 & 19 & 90 & 0.62 & 10 & 99 & 1.00 & 4 & 105 & 1 & 5 & 104 & 0.67 \\
\hline No & 47 & 6 & 41 & & 4 & 43 & & 1 & 46 & & 1 & 46 & \\
\hline
\end{tabular}

$\mathrm{P}=$ Positive, $\mathrm{N}=$ Negative, $\mathrm{P}=\mathrm{p}$-value. $\mathrm{B}$. henselae=Bartonella henselae, $B$. vinsonii=Bartonella vinsonii, B. tamiae=Bartonella tamiae 
Table-3: Herd seroprevalence and titer of antibodies against B. henselae, B. vinsonii subspp. berkhoffii, and B. tamiae in positive buffaloes.

\begin{tabular}{|c|c|c|c|c|c|}
\hline Farm & $\begin{array}{l}\text { Number of } \\
\text { buffaloes }\end{array}$ & $\begin{array}{c}\text { Number of positive } \\
\text { buffaloes }(\%)\end{array}$ & Titer of B. henselae & $\begin{array}{l}\text { Titer of } B \text {. vinsonii } \\
\text { subspp. berkhoffii }\end{array}$ & Titer of B. tamiae \\
\hline $1 *$ & 11 & $4(36.4)$ & $1: 16$ & - & $1: 16,1: 16,1: 16$ \\
\hline $2 *$ & 6 & $2 * *(33.3)$ & $1: 16,1: 16$ & $1: 16$ & - \\
\hline 3* & 6 & $5(83.3)$ & $1: 16,1: 16,1: 16$ & $1: 32$ & $1: 16$ \\
\hline 4* & 14 & $6(42.9)$ & $1: 16,1: 16,1: 16,1: 16$ & - & $1: 16,1: 16$ \\
\hline 5 & 11 & - & - - & - & \\
\hline 6 & 12 & - & - & - & \\
\hline 7 & 12 & - & - & - & \\
\hline 8* & 12 & $2(16.7)$ & - & $1: 64,1: 16$ & - \\
\hline 9 & 9 & - & - & - & - \\
\hline $10 *$ & 7 & $1(14.3)$ & $1: 16$ & - & - \\
\hline 11 & 4 & - & - & - & - \\
\hline 12 & 8 & - & - & - & - \\
\hline 13 & 2 & - & - & - & - \\
\hline 14 & 1 & - & - & - & - \\
\hline 15 & 2 & - & - & - & - \\
\hline 16 & 2 & - & - & - & - \\
\hline 17 & 2 & - & - & - & - \\
\hline 18 & 1 & - & - & - & - \\
\hline 19 & 2 & - & - & - & - \\
\hline $20 *$ & 2 & $1(50)$ & $1: 16$ & - & - \\
\hline 21 & 1 & - & - & - & - \\
\hline $22 *$ & 1 & $1(100)$ & $1: 16$ & - & - \\
\hline 23 & 1 & - & - & - & - \\
\hline 24 & 9 & - & - & - & - \\
\hline $25^{*}$ & 3 & $1(33)$ & $1: 16$ & - & - \\
\hline 26 & 3 & - & - & - & - \\
\hline 27 & 6 & - & - & - & - \\
\hline 28 & 4 & - & - & - & - \\
\hline $29 *$ & 2 & $1(50)$ & - & $1: 16$ & - \\
\hline
\end{tabular}

*Positive farms containing positive water buffaloes, **one buffalo containing two antibodies against to $B$. henselae and B. vinsonii subspp. berkhoffii. B. henselae=Bartonella henselae, B. vinsonii=Bartonella vinsonii, B. tamiae: Bartonella tamiae

vectors such as lice from the buffaloes, and we did not identify Bartonella pathogens in those lice. Therefore, the mechanism through which the buffaloes acquired antibodies against Bartonella spp. remains unknown. It is necessary to clarify the knowledge gaps concerning the distribution of this bacterium, the genetic diversity, and the transmission mode among water buffaloes, related personnel, and ectoparasites.

\section{Conclusion}

This is the first seroprevalence report of antibodies against $B$. henselae, $B$. vinsonii subspp. berkhoffii, and B. tamiae in water buffaloes from South Thailand. Further epidemiological studies should be conducted, including extensive surveys and additional studies of ectoparasites covering more areas and large samples sizes, to understand the risk factors for this disease among water buffaloes, related personnel, and ectoparasites.

\section{Authors' Contributions}

KK, CS, WM, and IW: Collected the samples. DP: Provided technical help during the experiments. PS: Did the statistical analysis. SB: Designed the experiments and drafted and revised the manuscript. All authors read and approved the final manuscript.

\section{Acknowledgments}

The authors are grateful to the staff of the provincial Department of Livestock Development and the farmers for their assistance during sample collection. This study was supported by the research grant of Akkhraratchakumari Veterinary College, Thailand (number AVC 01/2021) and One Health Research Center, Walailak University, Nakhon Si Thammarat, Thailand.

\section{Competing Interests} interests.

The authors declare that they have no competing

\section{Publisher's Note}

Veterinary World remains neutral with regard to jurisdictional claims in published institutional affiliation.

\section{References}

1. Okaro, U., Addisu, A., Casanas, B. and Anderson, B. (2017) Bartonella species, an emerging cause of blood-culture-negative endocarditis. Clin. Microbiol. Rev., 30(3): 709-746.

2. Kosoy, M., Bai, Y., Sheff, K., Morway, C., Baggett, H., Maloney, S.A., Boonmar, S., Bhengsri, S., Dowell, S.F., Sitdhirasdr, A., Lerdthusnee, K., Richardson, J. and Peruski, L. (2010) Identification of Bartonella infections in febrile human patients from Thailand and their potential animal 
reservoirs. Am. J. Trop. Med. Hyg., 82(6): 1140-1145.

3. Prutsky, G., Domecq, J.P., Mori, L., Bebko, S., Matzumura, M., Sabouni, A., Shahrour, A., Erwin, P.J., Boyce, T.G. and Montori, V.M. (2013) Treatment outcomes of human bartonellosis: A systematic review and meta-analysis. Int. J. Infect. Dis., 17(10): 811-819.

4. Bai, Y., Malania, L., Alvarez, C., Moran, D., Boonmar, S., Chanlun, A., Suksawat, F., Maruyama, S., Knobel, D. and Kosoy, M. (2013) Global distribution of Bartonella infections in domestic bovine and characterization of Bartonella bovis strains using multi-locus sequence typing. PLoS One, 8(11): e80894.

5. Saengsawang, P., Kaewmongkol, G. and Inpankaew, T. (2021) Molecular detection of Bartonella spp. and hematological evaluation in domestic cats and dogs from Bangkok, Thailand. Pathogens, 10(5): 503.

6. Hassanin, A., An, J., Ropiquet, A., Nguyen, T.T. and Couloux, A. (2013) Combining multiple autosomal introns for studying shallow phylogeny and taxonomy of laurasiatherian mammals: Application to the tribe Bovini (Cetartiodactyla, Bovidae). Mol. Phylogenet. Evol., 66(3): 766-775.

7. Saengsawang, P., Kaewmongkol, G., Phoosangwalthong, P., Chimnoi, W. and Inpankaew, T. (2021) Detection of zoonotic Bartonella species in ticks and fleas parasitizing free-ranging cats and dogs residing in temples of Bangkok, Thailand. Vet. Parasitol., 25: 100612.

8. Tsai, Y.L., Lin, C.C., Chomel, B.B., Chuang, S.T., Tsai, K.H., Wu, W.J., Huang, C.G., Yu, J.C., Sung, M.H., Kass, P.H. and Chang, C.C. (2011) Bartonella infection in shelter cats and dogs and their ectoparasites. Vector Borne Zoonotic Dis., 11(8): 1023-1030.

9. Gonçalves, L.R., Teixeira, M.M.G., Rodrigues, A.C., Mendes, N.S., Matos, C.A., Pereira C.L., Machado, R.Z. and André, M.R. (2018) Molecular detection of Bartonella species and haemoplasmas in wild African buffalo (Syncerus caffer) in Mozambique, Africa. Parasitology, 4(15): 1-8.

10. Pangjai, D., Intachinda, S., Maruyama, S., Boonmar, S., Kabeya, H., Sato, S., Petkanchanapong, W., Wootta, W., Maskiet, W., Saisongkorh, W., Preedakoon, P., Mahaprom, C. and Sawanpanyalert, P. (2018) Isolation and phylogenetic analysis of Bartonella species from Rusa deer (Rusa timorensis) in Thailand. Comp. Immunol. Microbiol. Infect. Dis., 56: 58-62.

11. Renesto, P., Gouvernet, J., Drancourt, M., Roux, V. and Raoult, D. (2001) Use of rpoB gene analysis for detection and identification of Bartonella species. J. Clin. Microbiol., 39(2): 430-437.

12. Norman, A.F., Regnery, R., Jameson, P., Greene, C. and Krause, D.C. (1995) Differentiation of Bartonella-like isolates at the species level by PCR-restriction fragment length polymorphism in the citrate synthase gene. J. Clin. Microbiol., 33(7): 1797-1803.

13. R Core Team. (2021) R: A Language and Environment for Statistical Computing. R Core Team.

14. Breitschwerdt, E.B. (2014) Bartonellosis: One health perspective for an emerging infectious disease. ILAR J., 55(1): 46-58.

15. Kosoy, M., Bai, Y., Enscore, R., Rizzo, M.R., Bender, S., Popov, V., Albayrak, L., Fofanov, Y. and Chomel, B. (2016)
Bartonella melophagi in blood of domestic sheep (Ovis aries) and sheep keds (Melophagus ovinus) from the southwestern US: Cultures, genetic characterization, and ecological connections. Vet. Microbiol., 15(190): 43-49.

16. Erol, E, Jackson, C., Bai, Y., Sell, S., Locke, S. and Kosoy, M. (2013) Bartonella bovis isolated from a cow with endocarditis. J. Vet. Diag. Invest., 25(2): 288-290.

17. Dahmani, M., Sambou, M., Scandola, P., Raoult, D., Fenollar, F. and Mediannikov, O. (2017) Bartonella bovis and Candidatus Bartonella davousti in cattle from Senegal. Comp. Immunol. Microbiol. Infect. Dis., 50: 63-69.

18. Boularias, G., Azzag, N., Gandoin, C., Bouillin, C., Chomel, B., Haddad, N. and Boulouis, H.J. (2020) Bartonella bovis and Bartonella chomelii infection in dairy cattle and their ectoparasites in Algeria. Comp. Immunol. Microbiol. Infect. Dis., 70: 101450.

19. Inoue, K., Maruyama, S., Kabeya, H., Kawanami, K., Yanai, K., Jitchum, S. and Jittaparapong, S. (2009) Prevalence of Bartonella infection in cats and dogs in a metropolitan area, Thailand. Epidemiol. Infect., 137(11): 1568-1573.

20. Pangjai, D., Maruyama, S., Boonmar, S., Petkanchanapong, W., Wootta, W. and Sawanpanyalert, P. (2011) Seroprevalence of antibodies against Bartonella hensalae infection in cats and dogs along the Northern Borders of Thailand. Thai Vet. Med., 41(1): 95-98.

21. Srisanyong, W., Takhampunya, R., Boonmar, T., Kerdsin, A. and Suksawat, F. (2016) Prevalence of Bartonella henselae, Bartonella clarridgeiae, and Bartonella vinsonii subspp. berkhoffii in pet cats from four provincial communities in Thailand. Thai Vet. Med., 46(3): 663-670.

22. Kosoy, M., Morway, C., Sheff, K.W., Bai, Y., Cloborn, J., Chalcraft, L., Dowell, S., Peruski, L., Malony, S., Baggett, H., Sutthirattana, S., Sidhirat, A., Maruyama, S., Kabeya, H., Chomel, B., Kasten, R., Popov, V., Robinson, J., Kruglov, A. and Petersen, L. (2008) Bartonella tamiae spp. nov., a newly recognized pathogen isolated from three human patients from Thailand. J. Clin. Microbiol., 46(2): $772-775$.

23. Kabeya, H., Colborn, J.M., Bai, Y., Lerdthusnee, K., Richardson, J., Maruyama, S. and Kosoy, M. (2010) Detection of Bartonella tamiae DNA in ectoparasites from rodents in Thailand and their sequence similarity with bacterial cultures from Thai patients. Vector Borne Zoonotic Dis., 10(5): 429-434.

24. Pulliainen, A.T. and Dehio, C. (2012) Persistence of Bartonella spp. Stealth pathogens: From subclinical infections to vaso proliferative tumor formation. FEMS Microbiol. Rev., 36(3): 563-599.

25. Seki, N., Kasai, S., Saito, N., Komagata, O., Mihara, M., Sasaki, T., Tomita, T., Sasaki, T. and Kobayashi, M. (2007) Quantitative analysis of proliferation and excretion of Bartonella quintana in body lice, Pediculus humanus L. Am. J. Trop. Med. Hyg., 77(3): 562-566.

26. Promrangsee, C., Khositharattanakool, P., Somwang, P., Sunantaraporn, S., Phumee, A., Preativatanyou, K., Tawatsin, A., Brownell, N. and Siriyasatien, P. (2019) The prevalence of Bartonella bacteria in cattle lice collected from three Provinces of Thailand. Insects, 10(6): 152. 